\title{
Real-Time Diagnosis of Island Landslides Based on GB-RAR
}

\author{
Deming Ma ${ }^{1,2, *} \mathbb{C}$, Yongsheng $\mathrm{Li}^{3}{ }^{\circledR}$, Jianwei Cai ${ }^{4}$, Bingquan $\mathrm{Li}^{3}$, Yanxiong $\mathrm{Liu}^{1}$ and \\ Xingguo Chen ${ }^{5}$ \\ 1 The First Institute of Oceanography, Ministry of Natural Resources, Qingdao 266061, China; \\ xuanxuan235@163.com \\ 2 College of Environmental Science and Engineering, Ocean University of China, Qingdao 266100, China \\ 3 The predecessor of the Institute of crustal dynamics, China Earthquake Administration, Beijing 100085, \\ China; whlys@163.com (Y.L.); libingquan13@163.com (B.L.) \\ 4 China Center for Resource Satellite Data and Applications, Beijing 100094, China; bjqdlele@163.com \\ 5 Beijing Di Kong Software Technology Col, Ltd, Beijing 100097, China; chenxg@diksw.com \\ * Correspondence: demingma@fio.org.cn
}

Received: 30 January 2020; Accepted: 7 March 2020; Published: 12 March 2020

\begin{abstract}
Landslides are one of the most frequent and serious geological disasters that threaten people's lives and property safety. In recent years, with the rapid development of the coastal economy and the increasingly strained spatial resources, the island development activities have become extremely rapid, resulting in the frequent occurrence of landslides on the island. We selected Beichangshan Island in the north of China as the research area. By using high-precision ground-based real aperture radar (GB-RAR) measurement technology, the displacement changes of potential landslides are monitored continuously and dynamically to realize the real-time diagnosis and early warning of island landslides. At the same time, the data interpretation method and key processing flow are described in detail. The results show that during the whole monitoring process, an area of obvious change is found, which is mainly located in the middle of the landslide mass. The mean velocity rate shows a nonlinear deformation trend. The maximum deformation of the landslide in the five selected points reaches $4.5 \mathrm{~mm}$, which indicates that the area is in an unstable stage. The deformation monitoring ability of GB-RAR technology to identify the sub-millimeter level is demonstrated, and the monitoring method is verified. The validity and reliability of the method can be applied to real-time dynamic fine deformation diagnosis of island landslides. Its accuracy can meet the needs of dynamic change monitoring of island landslides, and it can become an important tool and means for early warning and treatment of landslides. The research is conducive to further enriching and improving the monitoring method system of island geological disasters in China, provides a scientific basis and technical support for early warning and disaster prevention and mitigation of island landslides, and can be popularized and applied in the monitoring of island landslides.
\end{abstract}

Keywords: GB-RAR; island landside; geologic hazard; real-time diagnosis; technical support

\section{Introduction}

An island is surrounded by the sea. With its special location, environment, resources, and other advantages, it has gradually become an important support for the development of the marine economy and the expansion of the marine industry. It is not only an important land territory and a second economic belt base on the sea but also an important fulcrum for building a marine ecological civilization and expanding blue economic space. Islands also play an important role in safeguarding national rights and national defense security $[1,2]$. China's coastal islands are located on the west side of the Pacific 
seismic belt, which is one of the most sensitive interfaces of global change and land sea interaction, and a typical vulnerable zone with frequent disasters [3,4]. With the rapid development of the coastal economy and the increasing shortage of space resources, island development activities have become extremely rapid in the past 20 years, resulting in frequent occurrence of geological disasters such as island landslides. It has seriously restricted the development of local economy, the improvement of islanders' living standards, and the sustainable development of islands, which has attracted more and more attention [5-11].

According to the geological hazard survey of 70 islands along the coast of China, 45 islands were found to have collapses and landslides, which occurred in both the south and the north $[6,12,13]$. Due to the relatively backward infrastructure construction and fragile ecosystem on the island, it is difficult to recover quickly once landslides occur, causing huge losses to the already backward island. Therefore, it is of great significance to carry out real-time monitoring and early warning of landslides on an island. Reasonable and effective monitoring means can not only help to understand and master the deformation and damage evolution process of island landslides but also helps to obtain geological disaster characteristics information of landslides. At the same time, it can provide reliable data and a scientific basis for landslide analysis, evaluation, monitoring, early warning and prevention. Finally, it is convenient for us to take corresponding disaster prevention and reduction measures in time to avoid and mitigate disasters.

The commonly used monitoring methods for landslide geological hazards mainly include traditional measurement methods (level, total station [14], etc.), GNSS [15], aerial photogrammetry [16], optical remote sensing [17], 3D laser scanning [18,19], spaceborne interferometric synthetic aperture radar (InSAR) technology [20], etc. GNSS refers to monitoring the position change of some fixed points on the landslide and is limited by the serious multi-path effect in the mountainous areas where satellite signals are easily blocked. The geodetic method is suitable for displacement monitoring in different deformation stages but is affected by terrain and weather; it has a long working period and poor continuous observation ability. Aerial photography and optical remote sensing are suitable for large-scale census but have low accuracy. 3D laser scanning can obtain point cloud data in real time; the result of it is greatly affected by the terrain's shape, accessibility etc. InSAR technology is suitable for the identification of hidden danger points and the investigation of dangerous situations in a large range of geological disasters, but it is limited by the low spatial resolution, fixed revisit period, and long-time baseline, so it has some limitations on the timeliness of landslide deformation emergency monitoring. In recent years, ground-based real aperture radar (GB-RAR) interferometry has become a new ground deformation monitoring method with real-time, dynamic, all-weather, high-resolution, and continuous space coverage characteristics. Unlike other comparable instruments, it does not use a synthetic aperture to attain good azimuth resolution. Compared with ground-based InSAR (GB-InSAR), GB-RAR uses real aperture radar (RAR), which has the advantages of wide scanning angle, large measuring range, and long monitoring distance [21]. In particular, its high precision capability up to millimeter or even sub-millimeter level is considered as an unprecedented new deformation observation technology. It has the ability of real-time and high-precision dynamic monitoring of target micro deformation [22,23], which effectively solves the above problems and opens a new way for real-time dynamic monitoring of island landslide micro deformation process.

GB-RAR interferometry is a new non-contact measurement technology based on the active imaging mode of microwave detection. Its working principle is to use microwaves to scan the target area and to coherently record the backscatter signal. After a series of processing operations such as focusing and filtering, the received echo information can acquire the synthetic aperture radar image. From the virtual part and real part of each complex number, the moment can be calculated, as well as the phase and amplitude information of the corresponding elements of the array. Then, through the radar interferometry technology, the phase information is used to calculate the displacement map, that is, the microwave signal is transmitted at two different times. According to the phase shift between the 
echoes of the two signals, the motion of the backscattered target is deduced to obtain the micro-shape variable of the monitored object [23].

GB-RAR interferometry is a powerful terrestrial technique, widely used to (a) detect the target (large man-made structures and ground, such as buildings, dams, and bridges) displacements [24-29], (b) monitor volcanic activity [30-33], and (c) observe glacier movement and avalanches [34-36]. In some cases, the system was used for controlling slope movements that threatened one or more lifelines [37-40]. Furthermore, in recent years, the GB-RAR interferometry technique has developed to an extent where it can significantly contribute to the management of major technical and environmental disasters, with applications in different risk scenarios [41-43], such as landslide-induced terrain deformations [43-48]. Therefore, the GB-RAR interferometry technique has proved its ability to be particularly suitable for monitoring landslides.

\section{Material and Methods}

\subsection{Study Area}

Changdao, also known as the Miaodao Archipelago, is located between Jiaodong Peninsula and Liaodong Peninsula, at the intersection of the Yellow Sea and the Bohai Sea, and is the connecting belt of the Bohai Sea economic circle. This area is rich in tourism resources and enjoys the reputation of "Xianshan on the sea" and "natural oxygen bar". Moreover, it is a national key scenic spot and National Nature Reserve. The North Changshan Island is located in the South Island Group of the Miaodao Islands, on the north side of the Changshan waterway, and is connected to the south and north of the South Changshan Island, with the geographical coordinates of $37^{\circ} 58.5^{\prime} \mathrm{N}$ and $120^{\circ} 42.5^{\prime}$ E. From a high-altitude aerial view, Beichangshan Island is nearly elliptical. The whole island is distributed in the NW direction, with a length of approximately $5.1 \mathrm{~km}$, a width of approximately $2.5 \mathrm{~km}$, an area of $8 \mathrm{~km}^{2}$, and a coastline of $15.4 \mathrm{~km}$. The highest point is located in the middle of Haoshan Mountain, with a height of approximately $195.7 \mathrm{~m}[49,50]$.

Beichangshan Island is a bedrock island [51]. The island body is mainly composed of quartzite, mixed with slate and phyllite [52]. The rock joint is perpendicular to the bedding, and the vertical joint fissures are developed, which makes the cliff in the northeast of the island body erect. In recent years, with the rapid economic development of Beichangshan Island, the disordered development of island resources has become increasingly serious, which has led to a series of geological disasters such as landslides, rock falls and collapses [53]; these have not only seriously affected the safety of life and property of tourists and villagers but also have become a major factor seriously restricting the development of tourism resources and sustainable economic development of Beichangshan Island. The mountain landslide in Shanhou village in the southeast of Beichangshan Island is taken as the research object. This area is located in the quarry of Shanhou village (Figure 1). Because the rock mass in Shanhou village is rich in weak structural planes [53-55], coupled with natural and human factors such as rainfall and slope toe excavation, a large area of landslide occurs in the rock mass (Figure 2). Many landslides have caused potential safety hazards to pedestrians, vehicles, roads, buildings, and other engineering facilities, and threatened the construction of the ring road and the restoration of the natural ecological environment. The real-time monitoring and early warning of landslides on Beichangshan Island is of great significance to the protection of the natural resources and the economic development of Beichangshan Island. At the same time, the monitoring and early warning method of landslide disaster on Beichangshan Island has played an exemplary role and can provide a scientific basis for landslide disaster prevention and mitigation on other islands. 


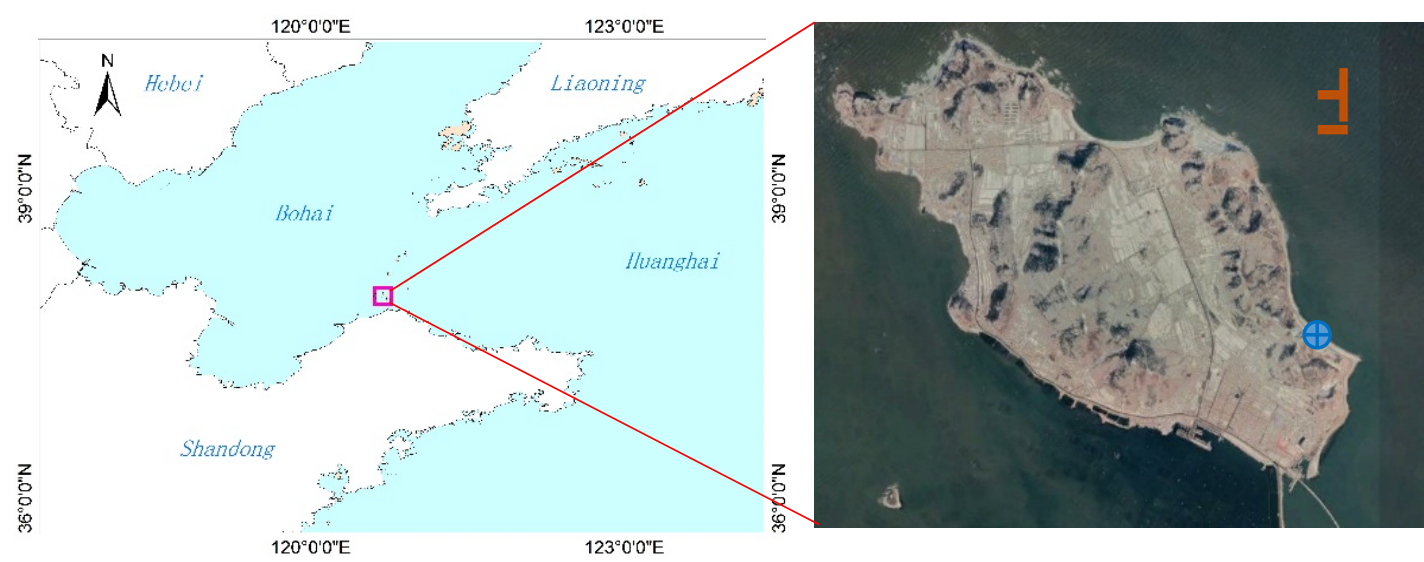

Figure 1. Landslide location of Beichangshan Island.

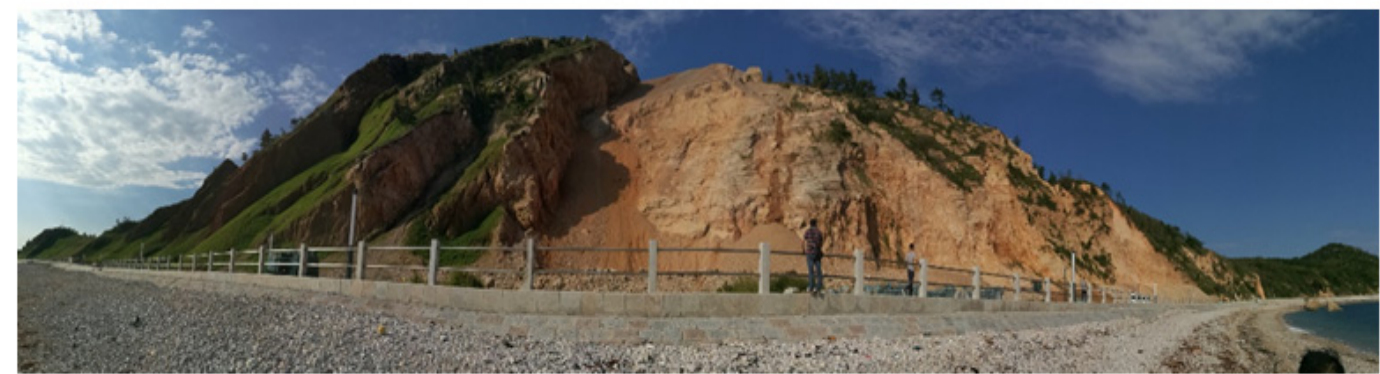

Figure 2. Landslide scene of Beichangshan Island.

\subsection{Data Acquisition}

In view of the potential secondary landslide geological hazards after the landslide on Beichangshan Island, in September 2018, a portable ground-based radar interferometry system (GPRI-II) produced by the Gamma Company of Switzerland was used to carry out the real-time monitoring of landslide geological hazards on the island, based on GB-RAR. Through multiple electromagnetic waves transmitting and receiving in $\mathrm{Ku}$ band, the phase change of each reflected signal was used to measure the geological hazards in millimeters. GPRI-II is an FMCW (Frequency Modulation Continuous Wave) radar interferometer equipped with a rotating scanner. It has two different data acquisition modes, rotated azimuth-scanning (RAS) and fixed azimuth scanning (FAS) [56]. The measuring distance can reach $10 \mathrm{~km}$. With the advantages of a flexible observation position and fast observation speed, it can work on a tripod, complete the installation within one hour, provide the interferometry measurement ability with a spatial baseline of $0.15-1 \mathrm{~m}$ (DEM (Digital Elevation Model) can be generated), and facilitate the monitoring of various types of deformation bodies with millimeter-level accuracy.

To make the installation as easy as possible, considering the site conditions and operation requirements, the location needs to have a wide view and facilitate the data collection of the equipment. The equipment was installed on the tripod, and the site layout of the equipment is shown in Figure 3. The monitoring distance is $0.05-0.25 \mathrm{~km}$. Considering the high angle slope, the antenna angle is set to 15 degrees, and the antenna azimuth is set to -30 to 80 degrees, which is conducive to signal reception. The acquisition time is from 10:04 a.m. to 15:35 p.m. for nearly 6 h. The Ku band microwave signal is used in the monitoring band, with a range resolution of $0.75 \mathrm{~m}$ and an azimuth resolution of $6.8 \mathrm{~m} / \mathrm{km}$. See Table 1 for detailed parameter settings. Data acquisition starts from the same location, and the time interval of data acquisition is approximately $5 \mathrm{~min} / \mathrm{scene}$. By using the phase change of the reflection signal to monitor the deformation information of the target area, a total of 72 images are obtained. Due to the close monitoring, the impact of external observation conditions such as temperature and humidity is not considered temporarily in this test. 
Table 1. GPRI-II equipment parameters.

\begin{tabular}{cc}
\hline Parameter Index & Value \\
\hline Frequency range & $17.1-17.3 \mathrm{GHz}$ \\
Effective measurement range & $50-250 \mathrm{~m}$ \\
Revisiting times & $5 \mathrm{~min}$ \\
Incidence angle & $15^{\circ}$ \\
Center azimuth angle & $260^{\circ}$ \\
\hline
\end{tabular}
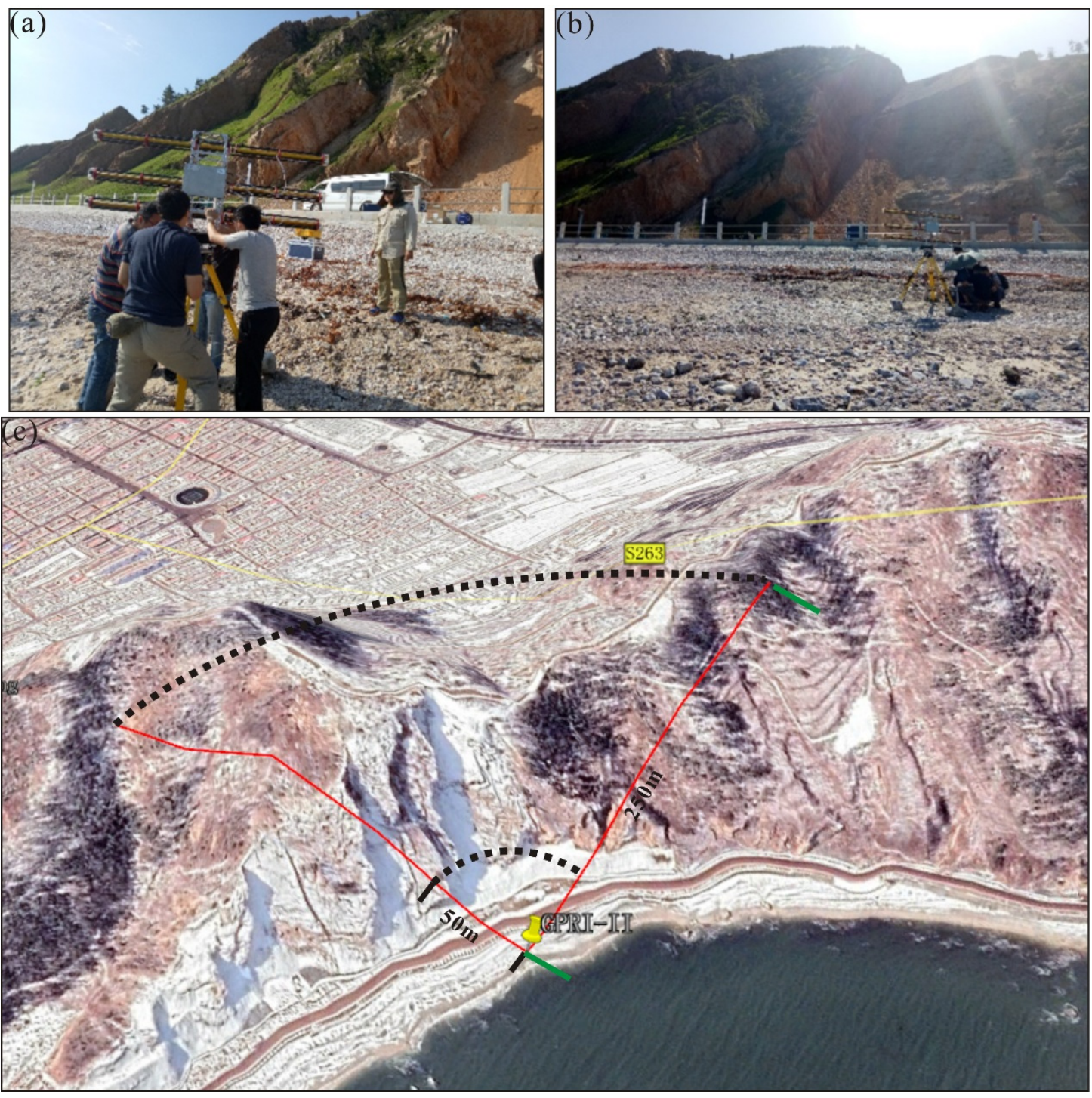

Figure 3. Equipment installation and data acquisition: (a) installation equipment; (b) data acquisition; (c) equipment location.

In this monitoring test, the nearest neighbour interference pair is used, and each image is set to form an interference pair with the two closest (by time) images, forming a master-slave image (In Figure 4, interferogram is abbreviated to IFG). According to the method shown in Figure 3, 207 interference pairs are generated, with a multi-view ratio of 1:20 and a coherence threshold of 0.6 . 


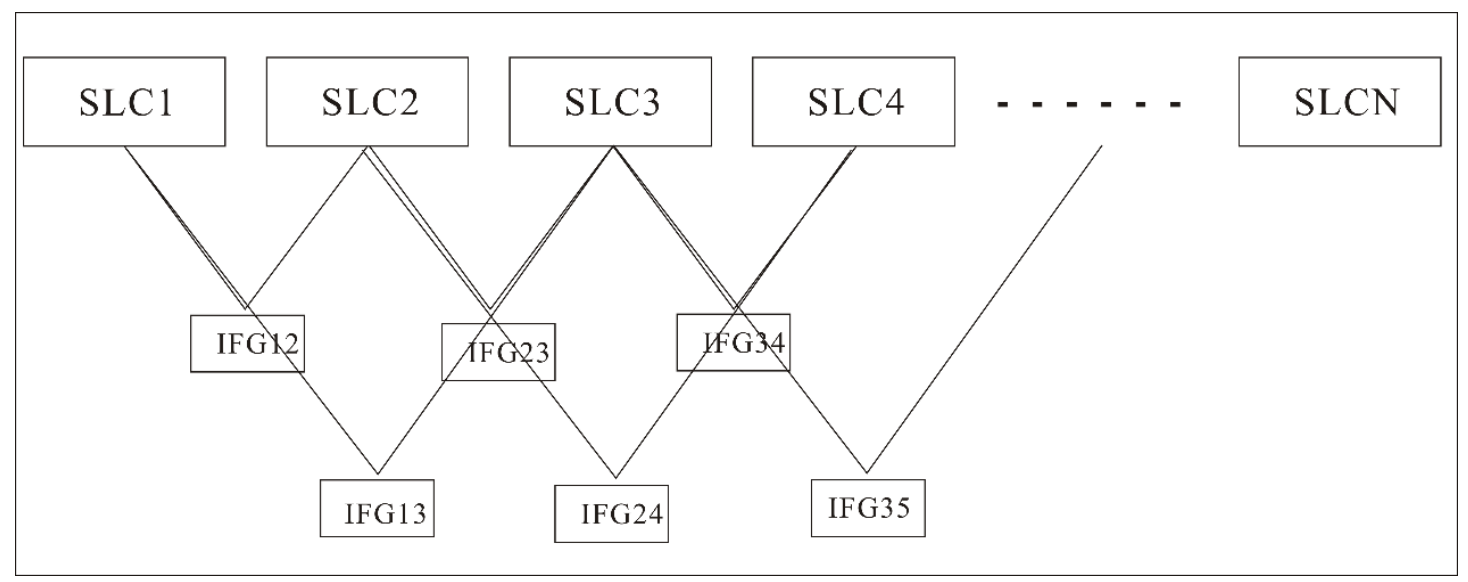

Figure 4. Schematic diagram of interference method.

\subsection{Data Analysis and Interpretation}

GPRI-II adopts a frequency modulation continuous wave (FMCW) system. Compared with the stepped frequency continuous wave (SFCW) radar system, the acquisition time of one scene of data is equivalent. GPRI-II integrates FMCW and InSAR technology to realize micro-deformation monitoring of ground targets. In general, the system adopts the continuous mode to continuously observe the target area [19].

The GPRI-II range resolution is:

$$
\Delta d_{\mathrm{sr}}=\frac{C}{2 B}
$$

where $C$ is the speed of light and $B$ is the bandwidth. In the formula, it can be seen that the range resolution is independent of the distance (the distance from the equipment to the observation target).

The GPRI-II azimuth resolution is:

$$
\Delta d_{\mathrm{az}}=\sin \left(\Theta_{-3 \mathrm{~dB}}\right) * R,
$$

where $\Theta_{-3 \mathrm{~dB}}$ is the half power wave velocity width and $R$ is the azimuth distance. The azimuth resolution is $6.28 \mathrm{~m}(1 \mathrm{~km})$, and the range resolution is $0.75 \mathrm{~m}$ [57].

Processing of GPRI-II raw data to single look complex (SLC) images is implemented within the software produced by the developer. The following steps are customized for the project. In the process of SLC images processing, interferograms are mainly formed by conjugate multiplication of two complex images, namely:

$$
s=s_{1} s_{2}^{*}=a_{1} a_{2} e^{j\left(\phi_{1}-\phi_{2}\right)} .
$$

Among them, $S_{1}$ and $S_{2}$ represent the backward reflection signal of the same target on the master-slave image, respectively; $a_{i}$ and $\phi_{i}(i=1,2)$ represent the strength and phase of the signal, respectively; and the superscript * represents the complex conjugate multiplication operator and the complex imaginary part.

$$
\varphi_{\text {int,ground }}=\varphi_{\text {def,ground }}+\varphi_{\text {baseline,ground }}+\varphi_{\text {atm,ground }}+\varphi_{\text {noise,ground }}
$$

Therefore, the interferometry phase of ground-based radar can be composed of four parts, namely, the atmospheric phase caused by the tropospheric delay, the baseline phase caused by the equipment center deviation, the deformation phase and the noise phase. In the interferometry phase of ground-based radar, the atmosphere $\varphi_{\text {atm,ground }}$ contains the tropospheric delay phase (mainly the influence of water vapour partial pressure). In the continuous observation mode, the baseline phase $\varphi_{\text {baseline,ground }}$ can be considered as nonexistent, without considering the influence of the error 
on deformation results, and the noise phase $\varphi_{\text {noise,ground }}$ is weakened by filtering. Therefore, when the atmosphere, baseline and noise phase are removed, the residual interferometry phase is the final deformation phase [58]. The data processing flow of ground-based interferometric radar is shown in Figure 5, which can be divided into the following 7 steps:

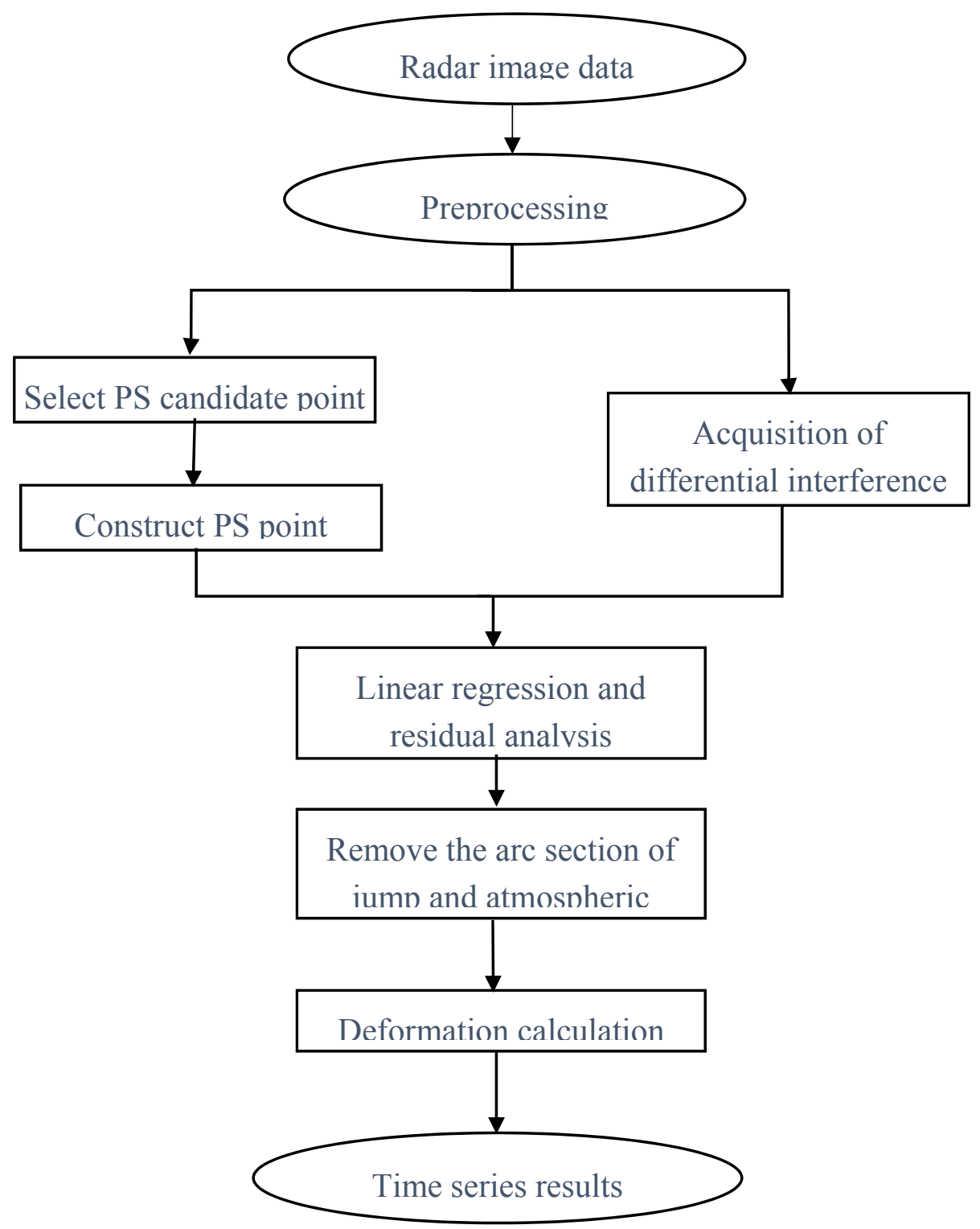

Figure 5. Time sequence processing flow of ground-based real aperture radar (GB-RAR).

(1) Data Preprocessing

Multi-phase SAR data preprocessing includes the selection of the reference image and SAR image registration. In the continuous observation mode of ground-based interferometric radar, image registration is not necessary. The selection of the reference image needs to meet the principle of maximizing the coherence of all interferometry pairs.

(2) Permanent Scatterer (PS) Point Selection

PS point recognition technology based on the time series SAR image includes the amplitude dispersion index method, signal-to-noise ratio threshold method, spectral diversity, coherence threshold method, phase threshold method or a combination of multiple indicators. Because of the high sampling frequency and the high signal-to-noise ratio of the ground-based interferometric radar, it is very 
suitable to use the amplitude dispersion index method based on the statistical characteristics to select points. The method can be expressed as follows:

$$
D_{\mathrm{a}}=\frac{\delta_{a}}{\mu_{a}}
$$

where $\delta_{a}$ is the standard deviation of the amplitude sequence and $\mu_{a}$ is the average value of the amplitude sequence. When the signal-to-noise ratio of the radar signal is greater than 4 , the amplitude tends to obey the normal distribution. In this case, the standard deviations of the time series phase and amplitude deviation are nearly equal. In this case, the points where both the vibration and phase tend to be stable can be selected simultaneously by using the amplitude deviation index.

(3) Differential Interferometry

According to the principle of short time-space baseline, the method of combination of multi-main images is used to generate differential interferograms, which increases the time sampling of the interference pairs to obtain more accurate deformation information. Because there is no baseline in the ground-based interferometric radar image under the continuous observation mode, only the time baseline image needs to be considered. The combination of the short time baseline can effectively avoid the large deformation phase and atmospheric phase in the differential interferogram and prevent the phase unwrapping and data analysis affected by the jump. As the ground-based radar in this experiment has been installed in the observation position, the radar baseline is zero. In this case, the differential interferometry phase of ground-based interferometry radar can be expressed as the composition of the deformation phase, atmospheric phase, and noise phase:

$$
\Delta \phi_{\text {int }}=\Delta \phi_{\text {def }}+\Delta_{\mathrm{at} m}+\Delta \phi_{\text {noise }}
$$

Among them, $\Delta \phi_{\text {int }}$ represents the phase of differential interference, $\Delta \phi_{\text {def }}$ represents the phase of deformation, $\Delta \phi_{\text {atm }}$ represents the phase of atmosphere, and $\Delta \phi_{\text {noise }}$ represents the phase of noise.

(4) PS Point Network

It is generally believed that the atmospheric components in the interferometry phase have spatial correlation, and the correlation is proportional to the distance. Therefore, the interferometry phase of the adjacent PS points can be differentiated again, which can further suppress the atmospheric phase. In this paper, according to the Delaunay triangulation principle, the selected PS points have meshed and the differential PS point arc segment was established. The arc segment stores the differential phase of PS points at both ends, which can be expressed as:

$$
\Delta \Delta_{\mathrm{int}, i, j}=\Delta \Delta_{\text {def }, i, j}+\Delta \Delta_{a t m, i, j}+\Delta \Delta_{\text {noise }}
$$

where, the $i, j$ distribution represents the sequence number of adjacent PS points, $\Delta \Delta_{\mathrm{atm}, i, j}$ and $\Delta \Delta_{\text {noise }}$ represent the differential atmosphere and noise phase between PS points, respectively.

(5) Linear Regression Calculation Parameters

If the distance between the PS points is very close, it can be considered that the atmospheric components in the differential phase of the above arc segment are basically removed, and the residual atmosphere and noise meet the normal distribution. In this case, the noise and residual atmospheric phase can be removed, and the deformation phase can be solved by linear regression. It should be noted that only the PS points at both ends of the arc segment are close to each other, and the parameters can meet the above assumptions. If the distance between the PS points at both ends of the arc segment is too large, the noise will not be suppressed and the phase jump will be introduced. The existence of the jump and atmospheric phase will increase the residual of regression results; therefore, by analyzing the results of the linear regression residual, we can identify the PS arc segment with the jump or residual atmospheric phase.

(6) High Residual Point Removal 
In traditional time-series differential interferometric deformation measurement technology, phase unwrapping is usually used to deal with the interferometry phase. Commonly used methods such as the branch cutting method, minimum norm method, and minimum cost flow method, all of which are based on their respective assumptions to restore the whole cycle part of the phase, can neither check the results nor evaluate the accuracy of the solution. In this paper, the interferometry phase is no longer unwrapped, but the residual is analyzed, and the PS arc with the jump is eliminated directly. This method avoids the introduction of entanglement error and increases the accuracy of linear regression results.

(7) Deformation Solution

After eliminating the arc section with the large residual, the residual atmosphere and noise phase meet the normal distribution, so the deformation results can be obtained by linear regression analysis again.

\section{Results and Discussion}

\subsection{Monitoring Results}

GB-RAR acquisitions have two types of observables: amplitude and phase. The amplitude is the back-scattered electromagnetic wave, which provides information on the reflectivity of the illuminated field. The stronger the backscatter (such as rock and artificial buildings) is, the greater the amplitude value is in the mean amplitude. The amplitude information is shown in Figure 6a, where more than 0 $\mathrm{dB}$ indicates the monitoring area with the reflected signal, less than $0 \mathrm{~dB}$ indicates the area without reflected signal in the mean amplitude. More than $0 \mathrm{~dB}$ indicates the area with reflected signal PS points that can be identified by using the amplitude dispersion index. The phase information reflects the distance change between the observation target and the radar. By means of differential interferometry, the deformation of the target point during the two measurements can be obtained and can be used to monitor the movement of the target. Generally, the coherence is used to evaluate the interferometry quality of the image. As shown in Figure $6 \mathrm{~b}$, close to red indicates the area with good coherence, close to blue indicates the area with poor coherence, and low coherence occurs in the vegetation coverage area, which is basically consistent with the actual vegetation coverage in the observation area.

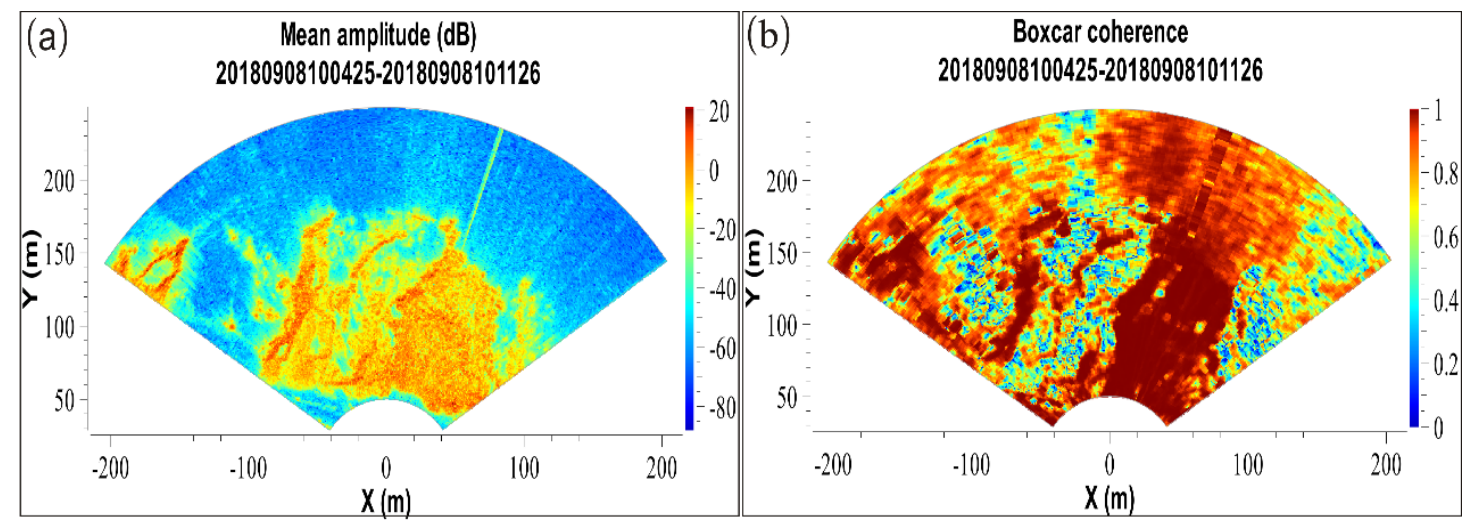

Figure 6. Mean amplitude and coherence maps: (a) mean amplitude; (b) boxcar coherence.

Computation of a successful InSAR time series analysis heavily relies on the performance of phase unwrapping. In this study, the detection and identification of unwrapping errors was accomplished. Assuming a set of three interferograms formed by three complex SAR images, the interferometric phase on the three interferograms is $\left(\phi_{\operatorname{lm}}, \phi_{\mathrm{mn}}, \phi_{\mathrm{ln}}\right)$. The phase misclosure threshold for the identification of unwrapping errors is empirically and conservatively set as $\pi$, namely an unwrapping error was defined by $\left|\phi_{\operatorname{lm}}+\phi_{\mathrm{mn}}+\phi_{\ln }>\pi\right|$. As can be seen from the results in Figure 7, phase unwrapping count is very low. 
Figure 8 shows the average deformation rate of the radar line of sight direction processed by the PS method. In the figure, the blue (negative value) indicates that the observation target is moving towards the radar direction, which is shown as moving downward along the slope in practice, that is, the area is covered by the soil falling from its upper part; the red (positive value) indicates that the target is moving away from the radar direction, which is shown as moving upward along the slope in practice. Figure 6 shows that the deformation rate obtained in this experiment is basically negative, i.e., the slope surface shows downward sliding, and there is an obvious active area in the middle of the landslide area, which is located in the middle part of the landslide. This deformation area is mainly caused by the workers on both sides of the left and right slope, and it falls from the top to the bottom, resulting in the sliding of the debris above the landslide body, which is consistent with the actual situation.

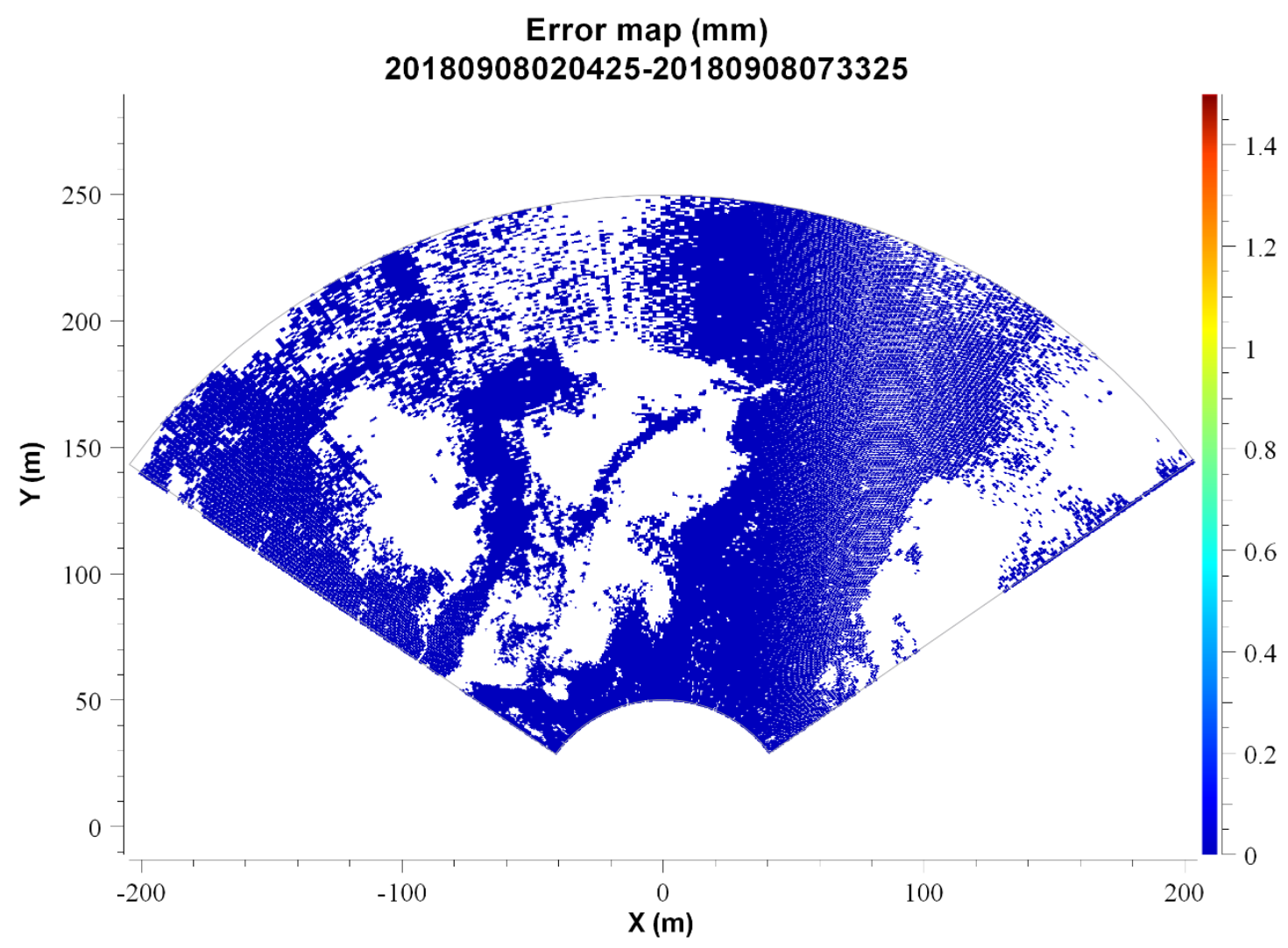

Figure 7. Unwrapping errors. 


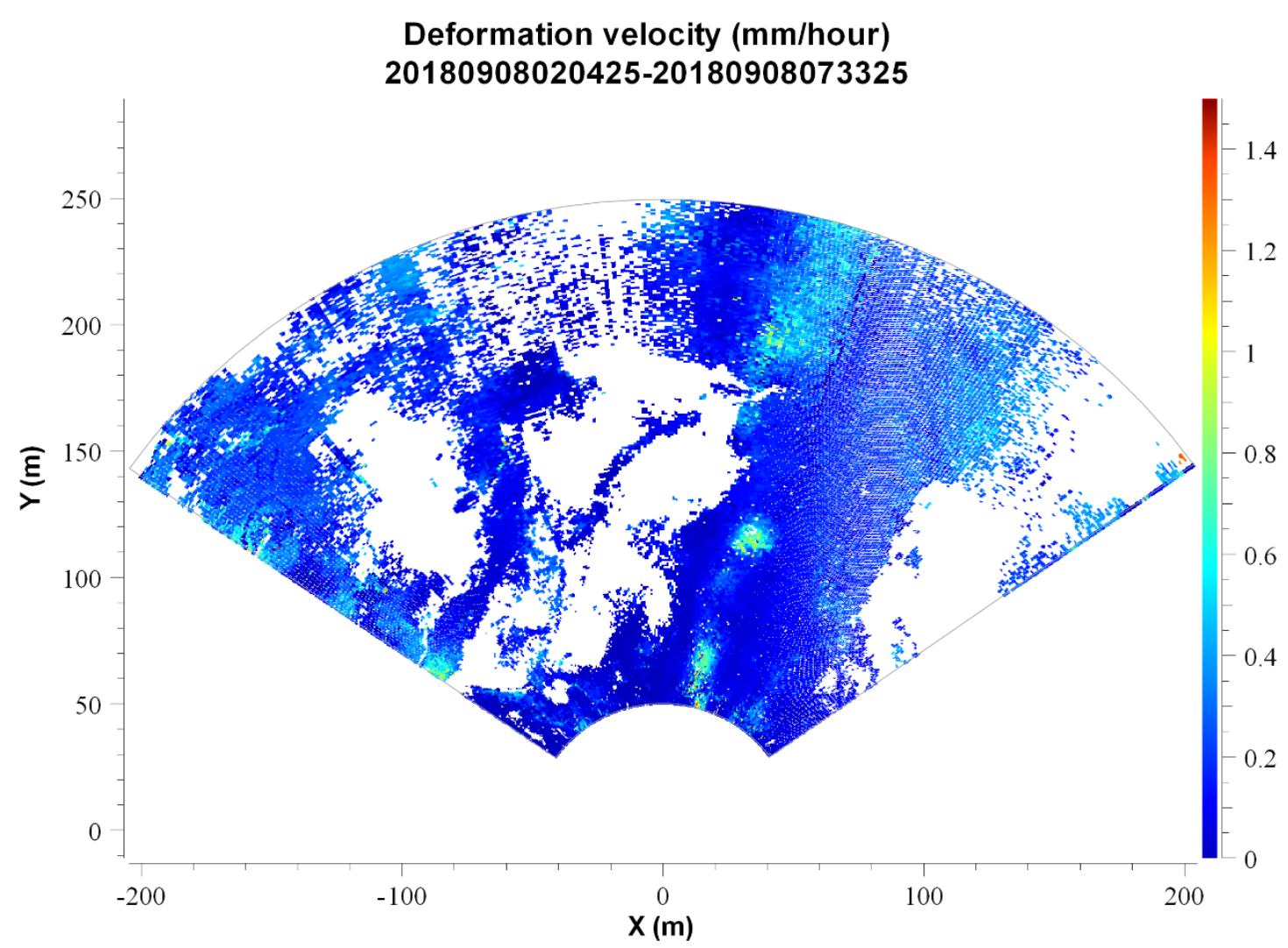

Figure 8. The deformation velocity rate map.

\subsection{Single Point Timing Analysis}

To further identify potential secondary landslides, we selected 5 points for long-term sequence deformation analysis, which are located in the middle of the landslide, at the bottom of the slope and 2 points away from the slope (Figure 9). Then, the deformation and time of each stage are plotted (Figure 10), in which the abscissa represents the time of data acquisition; the ordinate is the shape variable of each observation time compared with the previous time (acquisition time is 10:04).

It can be seen from Figure 10 that the points 1, 2, and 3 at the middle and bottom of the landslide have changed significantly during the observation process, and the average rate shows a nonlinear increase, indicating that the area is in an unstable state. Points 4 and 5 far away from the slope are basically unchanged and stable. In the first four hours, no deformation occurred at point 3 , and the change mainly occurred at approximately 12:50 p.m. However, point 2 directly below point 3 did not deform in the first four hours, and the change also occurred at approximately 12:50 p.m., with the maximum deformation reaching $4.5 \mathrm{~mm}$. The main reason for the deformation of points 2 and 3 is that the artificial slope protection project was carried out after the last island landslide. At that time, some staff were cleaning up the site from above, and the debris sliding from the top to the bottom led to the deformation during the monitoring period. Point 2 is just below point 3 , so the deformation time of points 2 and 3 is basically consistent with the actual situation. Point 1 is located at the bottom of the slope, and the deformation occurs after 2 p.m., and the maximum deformation also reaches $4.5 \mathrm{~mm}$, which is also caused by the debris sliding from the top to the bottom. Because point 2 and point 3 are located under the side, the deformation occurs later than at point 2. During the whole monitoring time, the deformation of points 4 and 5 is basically kept within $2 \mathrm{~mm}$. It can be considered that there is no deformation. These changes less than $2 \mathrm{~mm}$ may be caused by wind blowing or by atmosphere and noise. 


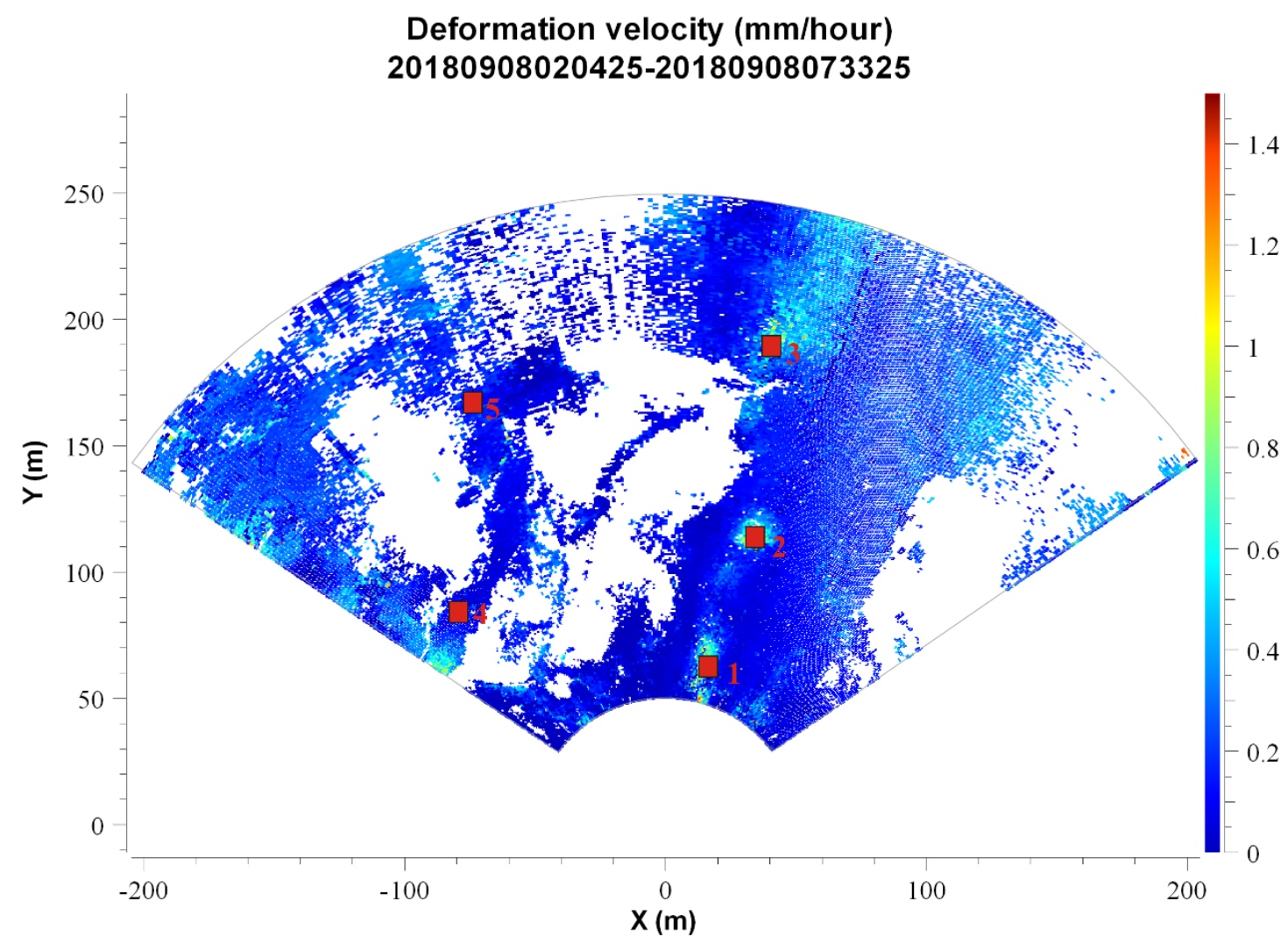

Figure 9. Sketch map of 5 selected points.

Displacement time series

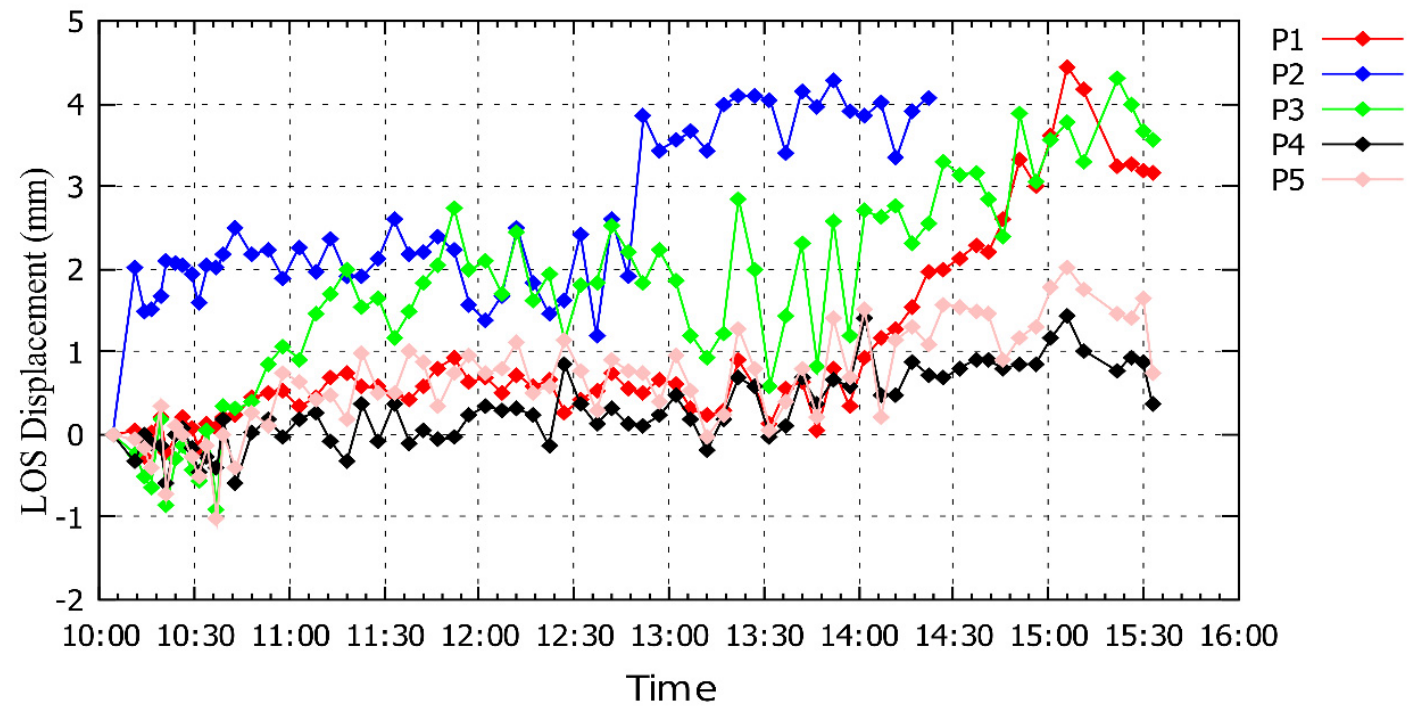

Figure 10. Deformation of each selected point during the monitoring period.

\section{Conclusions}

In this paper, according to the large-area landslide disaster of Beichangshan Island, we propose to use GB-RAR interferometry technology to carry out real-time diagnosis on the micro-deformation of the landslide geological disaster of the island and elaborate the data processing flow in detail. The real-time and reliable landslide deformation image in nearly six hours has been successfully obtained, which verifies the millimeter-level monitoring accuracy of the ground-based radar and the effectiveness and reliability of the monitoring method. This technology expands the means of 
surface deformation monitoring, enriches the monitoring methods of the research on the geological hazards of the island landslides in China, and improves the monitoring ability of the island landslides, providing information support and a reference basis for the early warning and prevention of the landslides on Beichangshan Island, to avoid the loss of life and property caused by the disasters to the maximum extent.

(1) Compared with conventional monitoring methods, GB-RAR interferometry technology is a non-contact measurement method that can realize real-time, dynamic, and high-precision automatic monitoring of dangerous island landslides. It can not only obtain single point deformation information but also grasp the overall change of unstable areas, and can provide a real continuous spatiotemporal deformation map of the measured area.

(2) Through data processing and analysis, the deformation evolution characteristics after a landslide disaster show that the monitoring area is in an unstable state and there is a risk of a secondary landslide. Therefore, effective measures should be actively taken to prevent the occurrence of a potential secondary landslide on the island.

(3) Through the continuous observation of the landslide disaster, the technical method presented in this paper shows the radar reflection intensity and coherence distribution in the landslide disaster area with remarkable characteristics and intuitively presents the change process and micro-deformation information of the landslide geological disaster in the form of a high-precision $(0.1 \mathrm{~mm})$ image displacement map, which provides a new option and tool for rapid and accurate diagnosis of an island landslide.

Although we have achieved high-precision and real-time monitoring of the landslide disaster in the monitoring area, GB-RAR interferometry technology obtains the deformation information of radar line of sight. How to obtain the three-dimensional deformation information is the direction that needs further research. At the same time, with the development of the big data era, how to realize the effective fusion and integration of the GB-RAR interferometry image and other sensor data will be an important research direction. The monitoring results are usually displayed on web-dashboards, allowing a strong decision support. It is believed that the application prospect of GB-RAR interferometry technology will be broader in the future.

Author Contributions: Conceptualization, D.M.; methodology, D.M. and Y.L.; software, X.C.; investigation, D.M., Y.L., J.C., B.L., Y.L. and X.C.; data curation, J.C. and B.L.; writing-review and editing, D.M. and B.L.; supervision, Y.L. All authors have read and agreed to the published version of the manuscript.

Funding: This research was funded by the public science and technology research funds projects of ocean, grant number 201405028 and the ministry of natural resources project, grant number SY1219001 and FZ1019009.

Conflicts of Interest: The authors declare no conflict of interest.

\section{References}

1. Yang, B.J.; Lü, C.X. Protection, exploration and management of oceanic islands in China. China Dev. 2009, 9, $10-14$.

2. Jiang, B.G.; Han, L.M. Scientifically exploiting island resources, and providing room for china's blue economic development. J. Ocean Univ. China 2011, 6, 28-31.

3. Niu, W.Y. The discriminatory index with regard to the weakness, overlapness, and breadth of ecotone. Acta Ecol. Sincica 1989, 9, 97-105.

4. Xu, Y.Q.; Liu, L.J.; Li, P.Y.; Du, X.Y.; Li, P.; Zhang, X.L.; Gao, W. Geology disaster feature and genetic analysis of typical islands, China. Acta Oceanol. Sin. 2015, 37, 71-83.

5. Gao, W.; Li, P.; Fu, M.Z.; Gao, S.; Li, P.Y. Characteristics and developing trend of typical island and geological disasters in Hainan Province. Ocean Dev. Manag. 2014, 31, 59-65.

6. Liu, L.J.; Gao, S.; Li, P.Y.; Gao, W.; Li, S.H.; Li, P.; Chen, B.Q.; Du, J. Characteristics and genesis of geological hazards in the Dongshan Island, Fujian Province. Acta Oceanol. Sin. 2015, 37, 137-146.

7. Du, J.; Li, P.Y.; Li, P.; Gao, S. The seabed stability zonation based on the marine geohazards evaluation in China. Acta Oceanol. Sin. 2014, 36, 124-129. 
8. Han, Z.N.; Gao, W.; Li, S.H.; Gao, S. Analysis of the main characteristics of geological hazards in four islands of northern Fujian Province. Coast. Eng. 2012, 31, 39-46.

9. Li, S.H.; Liu, L.J.; Gao, W. Geo-hazard classification in Dongshan Island of Fujian Province. Mar. Geol. Front. 2013, 29, 45-52.

10. Gao, W.; Liu, L.J.; Liu, J.; Xu, Y.Q.; Li, P.; Li, P.Y.; Xu, G.B. Formation mechanism and evolution of Beichangshan Island coast landslide in Shandong Province. Acta Oceanol. Sin. 2016, 38, 100-109.

11. Li, P.; Liu, J.; Xu, Y.Q.; Gao, W. Main geological disasters in typical islands and preventive measures in China. Ocean Dev. Manag. 2018, 5, 60-64.

12. Shi, X.F.; Sun, H.; Long, C.; He, H.W. Investigation on current situation of residents islands and countermeasures in Guangdong Province. Ocean Dev. Manag. 2015, 32, 41-48.

13. Liu, L.J.; Li, P.Y.; Wang, D.L.; Zhao, K.; Gao, W.; Li, P. Monitoring system designing and practicing for the qurry slope on rock island: A case study of Beichangshan island, Shandong Province. Adv. Mar. Sci. 2019, 37, 140-149.

14. Artese, G.; Perrelli, M.; Artese, S.; Manieri, F. Geomatics activities for monitoring the large landslide of Maierato, Italy. Appl. Geomat. 2015, 7, 171-188. [CrossRef]

15. Wang, G.Q. GPS landslide monitoring: Single base vs network solutions-A case study based on the Puerto rico and virgin islands permanent GPS network. J. Geod. Sci. 2011, 1, 191-203. [CrossRef]

16. Li, Z.B.; Shi, W.Z.; Lu, P.; Yan, L.; Wang, Q.M.; Miao, Z.L. Landslide mapping from aerial photographs using change detection-based markov random field. Remote Sens. Environ. 2016, 187, 76-90. [CrossRef]

17. Hervás, J.; Barredo, J.I.; Rosin, P.L.; Pasuto, A.; Mantovani, F.; Silvano, S. Monitoring landslides from optical remotely sensed imagery: The case history of Tessina landslide, Italy. Geomorphology 2003, 54, 63-75. [CrossRef]

18. Prokop, A.; Panholzer, H. Assessing the capability of terrestrial laser scanning for monitoring slow moving landslides. Nat. Hazards Earth Syst. Sci. 2009, 9, 1921-1928. [CrossRef]

19. Zhou, H.; Liu, L.J.; Wang, D.L.; Li, P.; Gao, W.; Zhou, Q.J.; Yang, Q.L. The application of landslide monitoring system in Shanhou village of the northern Changshan island in landslide monitoring. Acta Oceanol. Sin. 2016, 38, 124-132.

20. Li, B.Q.; Li, Y.S.; Jiang, W.L.; Cai, J.W.; Gan, J. Research and application slope dynamic monitoring based on ground-based real aperture radar. Geomat. Inf. Sci. Wuhan Univ. 2019, 44, 1093-1098.

21. Werner, C.; Strozzi, T.; Wiesmann, A.; Wegmüller, U. A Real-Aperture Radar for Ground-Based Differential Interferometry. In Proceedings of the Geoscience and Remote Sensing Symposium, IGARSS 2008, Boston, MA, USA, 7-11 July 2008; IEEE: Piscataway, NJ, USA, 2008.

22. Giordan, D.; Andrea, M.; Paolo, A.; Davide, B. Brief Communication: On the rapid and efficient monitoring results dissemination in landslide emergency scenarios: The Mont de La Saxe case study. Nat. Hazards Earth Syst. Sci. 2015, 15, 2008-2017. [CrossRef]

23. Ma, D.M.; Liu, Y.X.; Xu, W.X.; Wang, Y.B.; Gao, X.G. Monitoring process and key technology of GB-InSAR. Ocean Dev. Manag. 2018, 35, 81-85.

24. Casagli, N.; Farina, P.; Leva, D.; Nico, G.; Tarchi, D. Monitoring the Tessina Landslide by a Ground-Based SAR Interferometer and Assessment of the System Accuracy. In Proceedings of the IEEE International Geoscience \& Remote Sensing Symposium, Toronto, ON, Canada, 24-28 June 2002.

25. Tarchi, D.; Casagli, N.; Fanti, R.; Leva, D.; Luzi, G.; Pasuto, A.; Pieraccini, M.; Silvano, S. Landside Monitoring by Using Ground-Based SAR Interferometry: An example of application to the Tessina landslide in Italy. Eng. Geol. 2003, 68, 15-30. [CrossRef]

26. Noferini, L.; Pieraccini, M.; Mecatti, D.; Macaluso, G.; Atzeni, C.; Mantovani, M.; Marcato, G.; Pasuto, A.; Silvano, S.; Tagliavini, F. Using GB-SAR technique to monitor slow moving landslide. Eng. Geol. 2007, 95, 88-98. [CrossRef]

27. Herrera, G.; Ferandez-Merodo, F.A.; Mulas, J.; Pastor, M.; Luzi, G.; Monserrat, O. A landslide forecasting model using ground based SAR data: The Portalet case study. Eng. Geol. 2009, 105, 220-230. [CrossRef]

28. Casagli, N.; Catani, F.; Del Ventisette, C.; Luzi, G. Monitoring, prediction, and early warning using ground-based radar interferometry. Landslides 2010, 7, 291-301. [CrossRef]

29. Del Ventisette, C.; Intrieri, E.; Luzi, G.; Casagli, N.; Fanti, R.; Leva, D. Using ground based radar interferometry during emergency: The case of the A3 motorway (Calabria Region, Italy) threatened by a landslide. Nat. Hazards Earth Syst. Sci. 2011, 11, 2483-2495. [CrossRef] 
30. Nolesini, T.; Frodella, W.; Bianchini, S.; Casagli, N. Detecting slope and urban potential unstable areas by means of multi-platform remote sensing techniques: The Volterra (Italy) case study. Remote Sens. 2016, 8, 746. [CrossRef]

31. Di Traglia, F.; Intrieri, E.; Nolesini, T.; Bardi, F.; Del Ventisette, C.; Ferrigno, F.; Frangioni, S.; Tanteri, L.; Leva, D.; Casagli, N. The ground-based InSAR monitoring system at Stromboli volcano: Linking changes in displacement rate and intensity of persistent volcanic activity. Bull. Volcanol. 2014, 76, 786. [CrossRef]

32. Lombardi, L.; Nocentini, M.; Frodella, W.; Nolesini, T.; Bardi, F.; Intrieri, E.; Carla, T.; Solari, L.; Dotta, G.; Ferrigno, F.; et al. The calatabiano landslide (southern Italy): Preliminary GB-InSAR monitoring data and remote 3D mapping. Landslides 2017, 14, 685-696. [CrossRef]

33. Bardi, F.; Raspini, F.; Frodella, W.; Lombardi, L.; Nocentini, M.; Gigli, G.; Morelli, S.; Corsini, A.; Casagli, N. Monitoring the rapid-moving reactivation of Earth flows by means of GB-InSAR: The April 2013 Capriglio Landslide (Northern Appennines, Italy). Remote Sens. 2017, 9, 165. [CrossRef]

34. Martinez-Vazquez, A.; Fortuny-Guash, J. Monitoring Structural Changes and Stability of the Snow Cover with a Ground-Based Synthetic Aperture Radar. In Proceedings of the URSI 2005 Commission F Symposium on Microwave Remote Sensing of the Earth, Oceans, Ice, and Atmosphere, Ispra, Italy, 20-21 April 2005.

35. Luzi, G.; Pieraccini, M.; Mecatti, D.; Noferini, L.; Macaluso, G.; Tamburini, A.; Atzeni, C. Monitoring of an Alpine glacier by means of ground-based SAR Interferometry. IEEE Geosci. Remote Sens. Lett. 2007, 4, 495-499. [CrossRef]

36. Noferini, L.; Mecatti, D.; Macaluso, G.; Pieraccini, M.; Atzeni, C. Monitoring of belvedere glacier using a wide angle GB-SAR interferometer. J. Appl. Geophys. 2009, 68, 289-293. [CrossRef]

37. Casagli, N.; Del, V.C.; Mannucci, G.; La Rocca, L.; Ballini, A.; Antonello, G.; Fortuny-Guasch, J.; Tarchi, D.; Leva, D. Ground-based interferometry for monitoring an active rockslide in the Italian Alps. Geophys. Res. Abstr. 2008, 10, 08818.

38. Gigli, G.; Fanti, R.; Canuti, P.; Casagli, N. Integration of advanced monitoring and numerical modeling techniques for the complete risk scenario analysis of rockslides: The case of Mt. Beni (Florence, Italy). Eng. Geol. 2011, 120, 48-59. [CrossRef]

39. Bozzano, F.; Cipriani, I.; Mazzanti, P.; Prestininzi, A. Displacement patterns of a landslide affected by human activities: Insights from ground-based InSAR monitoring. Nat. Hazards 2011, 59, 1377-1396. [CrossRef]

40. Intrieri, E.; Gigli, G.; Nocentini, M.; Lombardi, L.; Mugnai, F.; Casagli, N. Sinkhole monitoring early warning an experimental and successful GB-InSAR application. Geomorphology 2015, 241, 304-314. [CrossRef]

41. Tarchi, D.; Casagli, N.; Moretti, S.; Leva, D.; Sieber, A.J. Monitoring landslide displacements by using ground-based radar interferometry: Application to the Ruinon landslide in the Italian Alps. J. Geophys. Res. 2003, 108. [CrossRef]

42. Broussolle, J.; Kyovtorov, V.; Basso, M.; Ferraro, G.; Morgado, J.F.; Giuliani, R.; Oliveri, F.; Sammartino, P.F.; Tarchi, D. MELISSA, a new class of ground based InSAR system. An example of application in support to the Costa Concordia emergency. ISPRS J. Photogramm. Remote Sens. 2014, 91, 50-58. [CrossRef]

43. Lombardi, L.; Nocentini, M.; Frodella, W.; Nolesini, T.; Bardi, F.; Intrieri, E.; Carla, T.; Solari, L.; Dotta, G.; Ferrigno, F.; et al. The calatabiano landslide (Southern Italy): Preliminary GB-InSAR monitoring data and remote 3D mapping. Landslides 2016, 76, 1-18. [CrossRef]

44. Antonello, G.; Casagli, N.; Farina, P.; Leva, D.; Nico, G.; Sieber, A.J.; Tarchi, D. Ground-based SAR interferometry for monitoring mass movements. Landslides 2004, 1, 21-28. [CrossRef]

45. Nico, G.; Leva, D.; Antonello, G.; Tarchi, D. Ground-based SAR interferometry for terrain mapping: Theory and sen-sitivity analysis. IEEE Trans. Geosci. Remote Sens. 2004, 42, 1344-1350. [CrossRef]

46. Corsini, A.; Farina, P.; Antonello, G.; Barbieri, M.; Casagli, N.; Coren, F.; Guerri, L.; Ronchetti, F.; Sterzai, P.; Tarchi, D. Space-borne and ground-based SAR interferometry as tools for landslide hazard management in civil protection. Int. J. Remote Sens. 2006, 27, 2351-2369. [CrossRef]

47. Barla, G.; Antolini, F.; Barla, M.; Mensi, E.; Piovano, G. Monitoring of the Beauregard landslide (Aosta Valley, Italy) using advanced and conventional techniques. Eng. Geol. 2010, 116, 218-235. [CrossRef]

48. Leva, D.; Nico, G.; Tarchi, D.; Fortuny-Guasch, J.; Sieber, A.J. Temporal analysis of a landslide by means of a ground-based SAR interferometer. IEEE Trans. Geosci. Remote Sens. 2003, 41, 745-752. [CrossRef]

49. Compilation Committee of China Island Records. China Island Records Shandong Volume I (North Coast of Shandong Province); China Ocean Press: Beijing, China, 2013. 
50. Ma, D.M.; Peng, W.; Chi, Y.; Shi, H.H.; Li, Z.G.; Liu, X.H. Study on estimation method of non-point source pollution load on island. China Environ. Sci. 2016, 36, 3150-3158.

51. Du, G.Y. Character and countermeasure of seawater intrusion on bedrock such as south and north Changshan island. Mar. Sci. 2002, 26, 55-59.

52. Zhu, Y.F.; Yin, Y.H.; Zhu, Z.W.; Yu, H.S. Origin and comprehensive assessment of marine geologic relics in Changdao island. Mar. Geol. Quat. Geol. 2005, 25, 115-120.

53. Yang, Q.Z. Study on Monitoring and Early Warning of Landside in Beichangshan Island; First Institure of Oceanography, SAO: Qingdao, China, 2017.

54. Xu, G.B. Study on the Stability of Island Rock Slope under Rainfall and Toe Quarrying; Qingdao University of Technology: Qingdao, China, 2014.

55. Meng, Q.K. Island Rock Slope Support Design and Stability Analysis; Qingdao University of Technology: Qingdao, China, 2015.

56. Zhang, B.C.; Ding, X.L.; Jiang, M.; Zhang, B.; Wu, S.B.; Liang, H.Y. Ground-Based Interferometric Radar for Dynamic Deformation Monitoring of the Ting Kau Bridge in Hong Kong. In Proceedings of the IGARSS 2016-2016 IEEE International Geoscience and Remote Sensing Symposium, Beijing, China, 10-15 July 2016.

57. Li, Y.S.; Jiao, Q.S.; Hu, X.H.; Li, Z.L.; Li, B.Q.; Zhang, J.F.; Jiang, W.L.; Luo, Y.; Li, Q.; Ba, R.J. Detecting the slope movement after the 2018 Baige Landslides based on ground-based and space-borne radar observations. Int. J. Appl. Earth Obs. Geoinf. 2020, 84, 101949. [CrossRef]

58. Cai, J.W. Integration of Ground-Based and Space-Borne Interferometer Radar for 3-D Deformation of Reclamation Area; China University of Geosciences (Beijing): Beijing, China, 2018.

(C) 2020 by the authors. Licensee MDPI, Basel, Switzerland. This article is an open access article distributed under the terms and conditions of the Creative Commons Attribution (CC BY) license (http://creativecommons.org/licenses/by/4.0/). 